\title{
Sêmen bovino sexado: A produção in vitro de embriões pode ser influenciada pelo touro doador do material genético?
}

\author{
Bovine sexed semen: Is the in vitro embryo production influenced by the donor of the genetic mate- \\ rial? \\ Priscila Rodrigues Serafim ${ }^{\dagger}$, Gustavo Mendes Gomes ${ }^{\S}$, Letícia Patrão de Macedo Gomes ${ }^{\S}$, Joana \\ Larissa Barbosa Born ${ }^{\dagger}$, Marcelo Sant'Ana Borges ${ }^{\dagger}$, André Maciel Crespilho ${ }^{\dagger \$^{*}}$
}

Como citar esse artigo. Serafim, PR; Gomes, GM; Gomes, LPM; Born, JLB Borges, MS; Crespilho, AM. Sêmen bovino sexado: A produção in vitro de embriões pode ser influenciada pelo touro doador do material genético? . Revista de Saúde. 2018 Jan./Jun.; 09 (1): 04-08

\begin{abstract}
Resumo
O estudo teve por objetivo avaliar a possível influência do touro doador de sêmen sexado na taxa de formação de blastocistos e resultados de concepção de embriões produzidos in vitro. Para o estudo foram utilizadas 29 vacas holandesas doadoras de embriões oriundas de uma única fazenda pertencente à iniciativa privada. As doadoras foram selecionadas de acordo com sua produção leiteira, histórico reprodutivo e mérito genético e foram submetidas à aspiração folicular e posterior seleção de ovócitos viáveis, que foram fertilizados com material genético sexado de fêmea de 7 touros da raça Gir. A taxa de formação de embriões no cultivo in vitro e índices de concepção pós-transferência de embriões (TE) foram computados e analisados através de teste Qui-quadrado utilizando software Graph Pad Prism Instat 5.0®, considerando nível de significância de 5\%.

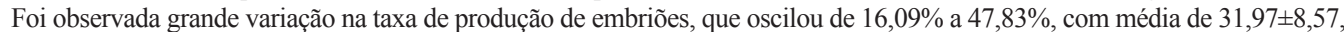
havendo tendência de influência do touro/sêmen sexado sobre as taxas de formação de blastocistos $(\mathrm{P}=0.0659)$. Na taxa de concepção dos embriões transferidos observou-se efeito significativo exercido pelo sêmen sexado ( $\mathrm{p}=0.0230)$, com resultados oscilando entre $12,5 \%$ a $77,78 \%$, na dependência do touro doador do sêmen. Conclui-se que existe variação nas taxas de produção embrionária e na fertilidade de embriões produzidos in vitro de acordo com o touro doador do sêmen sexado.
\end{abstract}

Palavras-chave: Embriões; Fertilização in vitro; Sêmen sexado; Touro.

\begin{abstract}
The objective of this study was to evaluate the influence of bull donor of sexed semen on in vitro blastocysts formation and pregnancy rates on bovine embryo transfer (ET) programs. For this experiment, 29 Holstein embryo donor cows from a single farm were selected based on milk production, reproductive history and genetic merit. The cows were submitted to follicular aspiration and selection of viable oocytes, which were fertilized with sexed semen from 7 Gir bulls. The rates of embryo production and the conception after ET were computed and analyzed using the Chi-square test (Graph Pad Prism Instat 5.0® software; $\mathrm{P}<0.05)$. A significative variation was observed on the embryo production rates, ranging from $16.09 \%$ to $47.83 \%$, with a mean of $31.97 \pm 8.57$. Tendency of bull/sexed semen influence was observed in the in vitro blastocyst formation ( $\mathrm{P}=0.0659)$, and bull effect was observed for the conception rates of transferred embryos $(\mathrm{P}=0.0230)$, with the results ranging from $12.5 \%$ to $77.78 \%$, depending on the donor of genetic material. In conclusion, there is huge variation in vitro embryo production rates and in the fertility index after ET, according to the donor of bull sexed semen.

Keywords: Bull; Embryo; In vitro fertilization; Sexed semen.
\end{abstract}

\section{Introdução}

As biotecnologias da reprodução são utilizadas como ferramenta para acelerar a produção, aumentar a eficiência reprodutiva além de promover o melhoramento genético do rebanho. A eficiência reprodutiva dos animais e a capacidade produtiva da propriedade é representada pela taxa de natalidade ${ }^{1}$. Além das biotecnologias que visam aumentar a concepção, há também meios de se pré-determinar o sexo do produto, possibilitando ao criador escolher o sexo de maior prevalência ou interesse em sua propriedade, focando assim no objetivo real do negócio, seja lácteo ou cárneo².

Atualmente, as técnicas validadas cientificamente para a seleção de gênero são as que se baseiam na diferença do conteúdo do DNA dos cromossomos sexuais presentes nas células espermáticas ${ }^{3}$. A pequena diferença no peso molecular dos cromossomos pode ser identificada através da citometria de fluxo, método utilizado comercialmente onde o DNA espermático é marcado com um corante fluorescente. As células marcadas são irradiadas com laser fazendo com que a partir da dispersão de luz (partículas maiores como a do cromossomo $X$ apresentam maior dispersão em relação ao Y), seja possível a separação dos distintos espermatozoides ${ }^{4,5}$.

Entretanto, embora a técnica de sexagem espermática tenha garantido maior eficiência ao processo de produção de bovinos de corte e leite, estudos com sêmen sexado tem demonstrado que a taxa

Afiliação dos autores: $\uparrow$ Universidade de Santo Amaro, UNISA, São Paulo-SP, Brasil.

§ Universidade de Vassouras, Vassouras-RJ, Brasil.

* Email para correspondencia: andremacc@yahoo.com.br 
de concepção com esse tipo de material pode ser inferior quando comparada ao sêmen convencional ${ }^{7}$. Tais diferenças provavelmente se justificam pelo estresse ao qual o espermatozoide é submetido para sua seleção, resultando em danos irreversíveis à ultraestrutura espermática ${ }^{8}$. No entanto, estudos anteriores sugeriram que a extensão e severidade dos danos sofridos pelos espermatozoides pode variar de acordo com o reprodutor doador do sêmen ${ }^{9,10}$.

Além disso, em função de limitações técnicas da separação sexual dos espermatozoides, sua utilização só é economicamente sustentável para a indústria quando doses de $2,1 \times 10^{6}$ de células espermáticas são criopreservadas, quantidade que corresponde a cerca de $10 \%$ do total de células presentes em uma dose de sêmen convencional ${ }^{7}$.

Embora seja possível a utilização do sêmen sexado junto a técnicas como inseminação artificial (IA) e inseminação artificial em tempo fixo (IATF), o uso dessa tecnologia possui maior interesse econômico quando associada a programas de fertilização in vitro (FIV), pois permite que um número reduzido de espermatozoides fecunde muitos ovócitos em curto período de tempo, otimizando os programas de melhoramento genético animal. De acordo com Araujo et al. ${ }^{11}$, a fertilização in vitro torna-se uma alternativa mais racional para o uso comercial do sêmen sexado, tendo em vista o reduzido número de espermatozoides disponíveis nas doses sexadas.

Reconhecendo que a técnica de sexagem pode resultar em menores taxas de concepção em relação ao uso do sêmen bovino convencional, o objetivo deste estudo foi verificar a influência do touro doador do sêmen sexado sobre a produção de blastocistos em sistema de produção in vitro, avaliando a taxa de concepção proporcionada por esses embriões quando transferidos para receptoras bovinas.

\section{Material e Métodos}

Para o estudo foram analisados dados retrospectivos da taxa de concepção de 7 touros da raça Gir, cujas amostras de sêmen sexado para fêmea foram obtidas junto às principais centrais de congelação e distribuição de sêmen do Brasil. As amostras de sêmen foram utilizadas para a produção in vitro de embriões bovinos obtidos a partir da aspiração folicular de 29 doadoras da raça Holandesa, pertencentes a uma única propriedade leiteira privada situada no Estado de Minas Gerais, Brasil (Latitude: $18^{\circ} 17^{\prime} 37^{\prime \prime} \mathrm{S}$; Longitude: $43^{\circ}$ 00 ' $33^{\prime \prime} \mathrm{W}$ ). Todas as vacas doadoras foram selecionadas de acordo com seu pedigree, histórico de produção leiteira e características zootécnicas próprias e de sua progênie, de acordo com o modelo de seleção animal empregado pela fazenda. As aspirações foliculares foram conduzidas pelo mesmo veterinário, utilizando ultrassonografia via transvaginal ("ovum pick-up", OPU), técnica menos traumática onde os folículos ovarianos visualizados são penetrados por agulha acoplada a um sistema de vácuo que proporciona aspiração do conjunto cumullus-ovócito.

Os ovócitos obtidos a partir da aspiração foram avaliados de acordo com a classificação proposta pela Sociedade Internacional de Transferência de Embriões $(\text { IETS })^{12}$, onde apenas estruturas de grau 1 foram selecionadas.

Para as fertilizações in vitro o material genético sexado e criopreservado de cada reprodutor foi descongelado em banho maria a $37^{\circ} \mathrm{C}$ durante 30 segundos, e submetido à centrifugação em gradiente de Percoll, segundo técnica descrita por Ball ${ }^{13}$. Após a seleção em Percoll foi utilizada uma concentração de $1 \times 10^{6} /$ espermatozoides móveis para fecundação dos ovócitos em sistema comercial de fertilização in vitro (FIV).

Cerca de 20 horas após a FIV os prováveis zigotos foram transferidos para sistema de cultivo in vitro (CIV) em estufa com atmosfera controlada a $38,5^{\circ} \mathrm{C}$ e $5 \%$ de $\mathrm{CO}_{2}$ onde permaneceram por 7 dias. A taxa de clivagem e formação de blastocistos foi avaliada, respectivamente, nos dias 3 e 8 do CIV.

Decorrida a etapa de CIV foram selecionados os blastocistos grau 1 (segundo classificação da IETS $^{12}$ ) para a transferência embrionária (TE). Para a TE foram selecionadas vacas receptoras utilizando os seguintes critérios: escore de condição corporal de 2,5 a 4 (Escala de 1 a 5 , segundo Ayres et al ${ }^{14}$ ); tonicidade uterina de medianamente relaxado a tônico na palpação retal; ovários funcionais com presença de um folículo dominante ou corpo lúteo $(\mathrm{CL})$ cíclico e sem indicativos de problemas reprodutivos.

Todas as receptoras foram submetidas ao seguinte protocolo de sincronização: em dia aleatório do ciclo estral (D0), no início da manhã, todos os animais receberam a colocação de um dispositivo intravaginal liberador de progesterona (P4) (Sincrogest $\AA$, Ouro Fino, São Paulo, Brasil; 1,0g de progesterona) associado à aplicação de 2,0 $\mathrm{mL}$ de Benzoato de Estradiol (Estrogin $\AA$, Biofarm, Jaboticabal, Brasil; 0,005 g) intramuscular (IM). No dia 8 (D8), no início da manhã, houve a retirada do dispositivo de $\mathrm{P} 4 \mathrm{e}$ foi administrado $2 \mathrm{~mL}$ de Cloprostenol Sódico (Sincrocio ${ }^{\circledR}$, Ouro Fino, São Paulo, Brasil; 0,25 mg/mL) IM; 0,3 mL de Cipionato de Estradiol (ECP ${ }^{\circledR}$, Pfizer, São Paulo, Brasil; 2 mg/ $\mathrm{mL}$ ) IM e 1,5 mL de Gonadotrofina Coriônica Equina (Folligon ${ }^{\circledR}$, MSD Saúde Animal, São Paulo, Brasil, $200 \mathrm{UI} / \mathrm{mL}$ ) IM.

No dia 18 (D18) as receptoras foram submetidas ao exame ginecológico e àquelas que apresentaram corpo lúteo receberam os blastocistos através de inovulação realizada no corno ipsilateralmente ao 
CL funcional. Todas as receptoras foram submetidas à anestesia epidural a base de $3 \mathrm{ml}$ de Lidocaína $2 \%$ sem vasoconstritor. As inovulações foram sempre conduzidas pela mesma equipe veterinária, realizando o procedimento de forma padronizada em todas as TEs.

Os dados gerados foram submetidos à análise estatística descritiva incluindo o cálculo das médias e desvio padrão para os parâmetros taxa de produção de blastocistos e taxa de concepção após a transferência dos embriões. Adicionalmente os touros foram identificados com números de 1 a 7 . As variáveis dependentes (taxa de produção e taxa de concepção dos embriões) foram analisadas utilizando-se teste Qui-quadrado através do software Graph Pad Prism Instat 5.0 $®$, considerando diferenças estatísticas quando $\mathrm{P}<0,05$ e tendências quando $0,05<\mathrm{P}<0,10$.

\section{Resultados}

Os resultados obtidos demonstraram grande variação nas taxas de produção de embriões, que oscilaram entre $16,09 \%$ a $47,83 \%$, com média de $31,97 \pm 8.57$, havendo uma tendência de influência do touro/sêmen sexado na taxa de produção de embriões ( $\mathrm{P}=0.0659$ ) (Quadro 1). Mesmo quando o material sexado do mesmo reprodutor foi utilizado em mais de uma rotina de FIV (touros 1 e 5) foi observada grande variação nos resultados da produção embrionária (Figura-1).

Por outro lado, efeito significativo do touro/ sêmen sexado foi observado para a taxa de concepção dos embriões transferidos ( $\mathrm{P}=0.0230)$ (Quadro 2).

Quadro 1. Resultados descritivos da produção de embriões em sistema de cultivo in vitro em função do touro doador de sêmen sexado.

\begin{tabular}{|c|c|c|c|}
\hline $\mathbf{N}^{\mathbf{0}}$ do Touro & $\mathbf{N}^{\mathbf{0}}$ de ovócitos viáveis & $\begin{array}{c}\mathbf{N}^{0} \text { de embriões } \\
\text { produzidos }\end{array}$ & $\begin{array}{c}\text { Taxa de produção } \\
\text { embrionária }\end{array}$ \\
\hline 1 & 79 & 26 & 32,91 \\
\hline 2 & 23 & 11 & 47,83 \\
\hline 3 & 78 & 19 & 24,36 \\
\hline 4 & 24 & 8 & 33,33 \\
\hline 5 & 87 & 14 & 16,09 \\
\hline 1 & 30 & 9 & 30,00 \\
\hline 6 & 68 & 24 & 35,29 \\
\hline 7 & 26 & 9 & 34,62 \\
\hline 5 & 54 & 18 & 33,33 \\
\hline Total & 469 & 138 & 29,42 \\
\hline Média geral & & & 31,97 \\
\hline
\end{tabular}

Quadro 2. Efeito do touro doador de sêmen sexado sobre a taxa de concepção de embriões produzidos in vitro e transferidos para receptoras previamente selecionadas e sincronizadas.

\begin{tabular}{|c|c|c|c|}
\hline $\mathbf{N}^{0}$ do Touro & $\begin{array}{c}\mathbf{N}^{\mathbf{0}} \text { de embriões } \\
\text { produzidoss }\end{array}$ & $\begin{array}{c}\text { Diagnóstico de } \\
\text { gestação }\end{array}$ & Taxa de concepção \\
\hline 1 & 26 & 11 & 42,31 \\
\hline 2 & 11 & 3 & 27,27 \\
\hline 3 & 19 & 4 & 21,05 \\
\hline 4 & 8 & 1 & 12,50 \\
\hline 5 & 14 & 2 & 14,29 \\
\hline 1 & 9 & 7 & 77,78 \\
\hline 6 & 24 & 11 & 45,83 \\
\hline 7 & 9 & 3 & 33,33 \\
\hline 5 & 18 & 10 & 55,56 \\
\hline Total & 138 & 52 & 37,68 \\
\hline Média geral & & & 36,66 \\
\hline
\end{tabular}




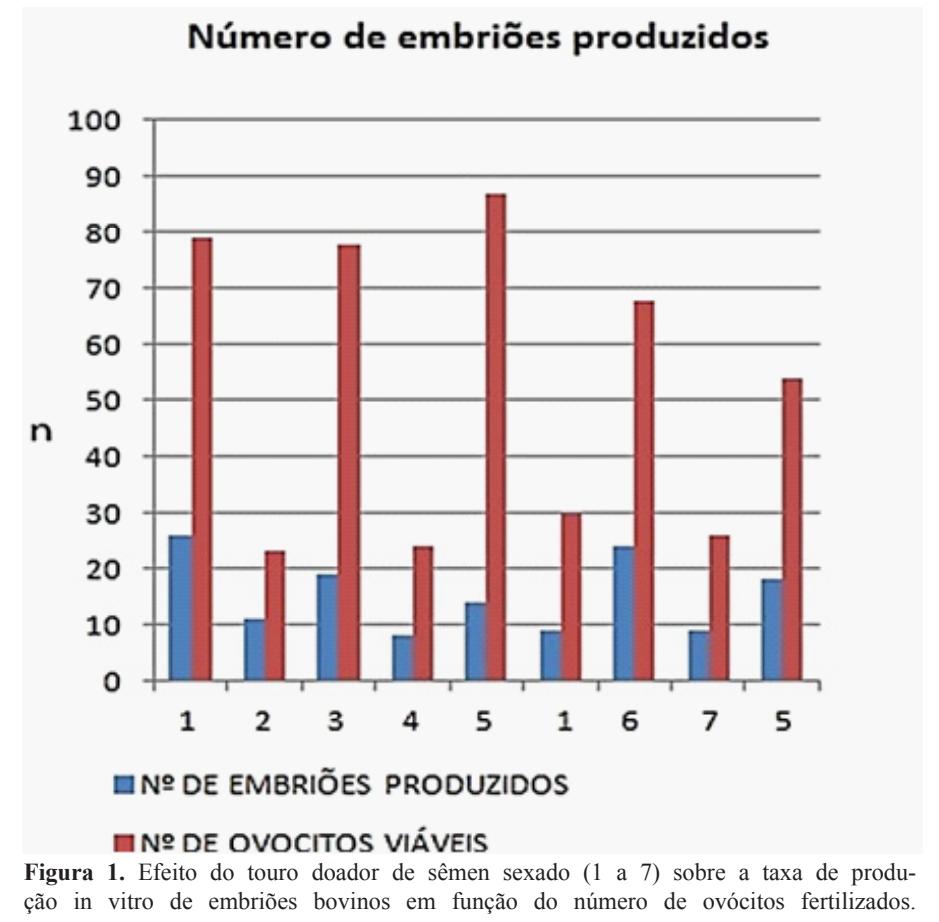

\section{Discussão}

No presente trabalho foi encontrada grande variação na taxa de produção de embriões até o estágio de blastocisto em função do touro produtor da dose de sêmen sexado. Quanto à taxa de concepção dos embriões produzidos in vitro, foi observado efeito significativo do touro doador sobre os índices de fertilidade. Tais resultados se assemelham aos reportados por Cebrian-Serrano et al. ${ }^{9}$ que descreveram que as diferenças de fertilidade encontradas podem apresentar relação direta com a qualidade do reprodutor, com a qualidade do próprio sêmen sexado ou dos oócitos empregados para os trabalhos de fertilização in vitro.

Assim como no estudo de Palma et al. ${ }^{15}$, foi observada grande amplitude nas taxas de formação de blastocistos de acordo com o touro doador do sêmen sexado. Uma possível explicação para tais diferenças pode estar relacionada a maior sensibilidade dos espermatozoides de alguns animais ao processo de sexagem. De acordo com Gosálvez et al. ${ }^{10}$, naturalmente espermatozoides produzidos por alguns reprodutores sofrem menor quantidade ou intensidade de danos durante o processo de sexagem. De acordo com Macedo et al. ${ }^{16}$, embora não completamente elucidadas tais diferenças entre indivíduos podem estar relacionadas as próprias variações observadas nas propriedades físicoquímicas das amostras espermáticas produzidas por diferentes touros.

Araújo et al. ${ }^{11}$ também apontaram grande variação entre os índices reprodutivos alcançados pelo sêmen sexado de diferentes reprodutores doadores de material genético. De acordo com os autores tais variações podem ser atribuídas a uma sensibilidade diferencial dos espermatozoides produzidos por touros distintos, o que ressalta a importância da seleção de animais que naturalmente produzem amostras espermáticas mais resistentes para serem utilizados em programas comerciais de sexagem espermática ${ }^{16}$.

Além das diferenças inerentes aos reprodutores, as variações nas taxas de concepção do sêmen sexado também podem ser atribuídas a fatores relacionados à qualidade dos oócitos empregados para a FIV 9 , menor longevidade e motilidade dos espermatozoides sexados ${ }^{17}$, maior peroxidação lipídica e fosforilação das lipoproteínas presentes na superfície da membrana plasmática ${ }^{18}$, além de capacitação prematura $^{19}$, lesões acrossomais ${ }^{20}$ e danos físicos à membrana plasmática ${ }^{21}$ das células espermáticas submetidas à separação sexual através da citometria de fluxo. Tais fatores, associados a susceptibilidade individual ${ }^{22}$, justificam as diferenças encontradas em nosso estudo.

\section{Conclusão}

A seleção de reprodutores com base não apenas 
no potencial de produção de espermatozoides, como também pela susceptibilidade de suas células espermáticas à citometria de fluxo, se torna imperativo para a plena implementação do sêmen sexado tendo em vista que a taxa de formação de blastocistos e fertilidade dos embriões produzidos in vitro sofrem influência individual dos touros cujo material genético é submetido ao processo de sexagem.

\section{Declarações}

Os autores declaram não possuir qualquer conflito de interesse, diretos ou indiretos, que podem influenciar os resultados do estudo.

\section{Referências Bibliográficas}

1. Côrrea CC, Veloso AF, Lima BM, Cota RG, Figueiredo Neto LF. Gerenciamento da pecuária de corte no Brasil: cria, recria e engorda de bovinos a pasto. In: Congresso da Sociedade Brasileira de Economia, Administração e Sociologia Rural. 2009; 47.

2. Rath D, Johnson LA. Application and commercialization of flow cytometrically sex-sorted semen. Reprod Dom Anim. 2008; 43: 338-346.

3. Garner DL. Flow cytometric sexing of mammalian sperm. Theriogenology. 2006; 65(5): 943-957.

4. Garner DL, Gledhill BL, Pinkel D, Lake S, Stephenson D, Van Dilla MA. Quantification of the X-and Y-chromosome-bearing spermatozoa of domestic animals by flow cytometry. Biol Reprod. 1983; 28:312-21

5. Johnson LA, Pinkel D. Modification of a laser based flow cytometer for high resolution DNA analysis of mammalian spermatozoa. Cytometry. 1986; 7(3): 268-273.

6. De Vries A, Overton M, Fetrow J, Leslie K, Eicker S, Rogers G. Exploring the impact of sexed semen on the structure of the dairy industry. Jour Dairy Sci. 2008; 91(2): 847-856

7. Seidel Jr GE. Sexing mammalian sperms and embryos. in: international congress on animal reproduction and artificial insemination, 11, 1988, Dublin. Proceedings ...Dublin: University College Dublin, 1988; 136-144.

8. Bermejo-Alvarez P, Rizos D, Rath D, Lonergan P, Gutierrez-Adan A. Epigenetic differences between male and female bovine blastocysts produced in vitro. Phys Gen. 2008; 32(2): 264-272.

9. Cebrian-Serrano A, Silvestre MA, Ruiz S, Rath D. Effect of sex-sorted sperm on development and quality of in vitro-produced bovine embryos derived from ovum pick up oocytes. Anim Sci Pap Rep. 2013; 31(2): 111122.

10. Gosálvez J, Ramirez MA, López-Fernández C, Crespo F, Evans KM, Kjelland ME, Moreno JF. Sex-sorted bovine spermatozoa and DNA damage: I. Static features. Theriogenology. 2011; 75(2): 197-205.

11. Araujo MS, Volpato R, Lopes MD. Produção de embriões bovinos in vitro com sêmen sexado. Rev Ed Cont Med Vet Zoot CRMV-SP. 2013; 11(3): 8-15

12. Stringfellow DA, Givens MD. Manual of the International Embryo Transfer Society: A Procedural Guide and General Information for the Use of Embryo Transfer Techology Emphasizing Sanitary Procedures. 2013.

ROCA; 2006.

13. Ball PJH, Peters AR. Reprodução em bovinos. 3ed. São Paulo:

14. Ayres H, Ferreira RM, Torres-Júnior JRS, Demétrio CGB, Lima CG, Baruselli PS. Validation of body condition score as a predictor of subcutaneous fat in Nellore (Bos indicus) cows. Liv Sci. 2009; 123(2): 175-179.

15. Palma GA, Olivier NS, Neumüller CH, Sinowatz F. Effects of sex-sorted spermatozoa on the efficiency of in vitro fertilization and ultrastructure of in vitro produced bovine blastocysts. Anat Hist Embryo. 2008; 37: 67-73.
16. Macedo GG, Sá Filho MF, Sala RV, Mendanha MF, Campos Filho EP, Baruselli PS. The use of sex-sorted sperm for reproductive programs in cattle. In Success in artificial insemination-quality of semen and diagnostics employed. InTech. 2013

17. Schenk JL, Suh TK, Seidel Jr GE. Embryo production from superovulated cattle following insemination of sexed sperm. Theriogenology. 2006; 65: 299-307.

18. Mocé E, Graham JK, Schenk JL. Effect of sex-sorting on the ability of fresh and cryopreserved bull sperm to undergo an acrosome reaction. Theriogenology. 2006; 66(4): 929-936

19. Tanno PH. Estudo das alterações morfo-funcionais de espermatozoides bovinos submetidos à sexagem por meio da técnica de citometria de fluxo [dissertação]. São Paulo: Universidade de São Paulo, Faculdade de Medicina Veterinária e Zootecnia. 2009; 100p.

20. Andrade RKO, Nascimento OS, Chaves MS, Moura MT, Guido SI, Bartolomeu CC. Uso de fluorocromos para avaliação do sêmen sexado de bovinos Girolando. Ciên Vet. 2015; 18: 269-272.

21. Parrilla I, Vasquez JM, Gil MA, Caballero I, Almiñana C, Roca J, Martinez EA. Influence of storage time on functional capacity of flow cytometrically sex-sorted boar spermatozoa. Theriogenology. 2005; 64(1): 86-98.

22. Suh T K, Schenk JL, Seidel Jr GE. High pressure flow cytometric sorting damages sperm. Theriogenology. 2005; 64(5): 1035-1048. 